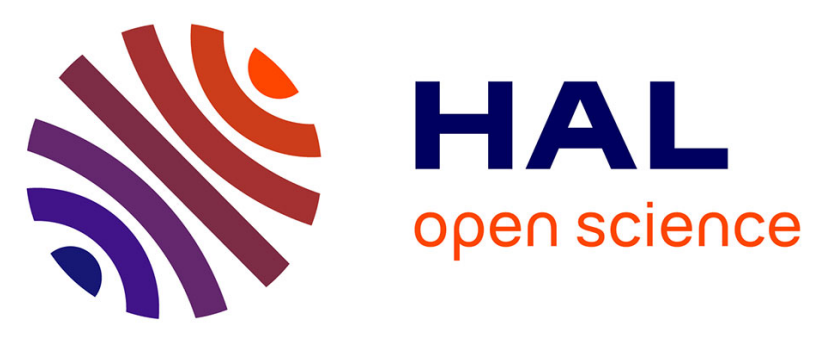

\title{
Efficient ultraviolet light frequency down-shifting by a thin film of $\mathrm{ZnO}$ nanoparticles
}

Aleksandra Apostoluk, Bruno Masenelli, Elsa Tupin, Bruno Canut, Dimitri Hapiuk, Patrice Melinon, Jean-Jacques Delaunay

\section{To cite this version:}

Aleksandra Apostoluk, Bruno Masenelli, Elsa Tupin, Bruno Canut, Dimitri Hapiuk, et al.. Efficient ultraviolet light frequency down-shifting by a thin film of $\mathrm{ZnO}$ nanoparticles. International Journal of Nanoscience, 2012, Selected Invited Papers from the Bilateral Conference between Canadian and French Researchers in Nanofabrication and Nanoscience; 11 (04), pp.1240022. 10.1142/S0219581X12400224 . hal-01965022

\section{HAL Id: hal-01965022 \\ https://hal.science/hal-01965022}

Submitted on 17 Jan 2022

HAL is a multi-disciplinary open access archive for the deposit and dissemination of scientific research documents, whether they are published or not. The documents may come from teaching and research institutions in France or abroad, or from public or private research centers.
L'archive ouverte pluridisciplinaire HAL, est destinée au dépôt et à la diffusion de documents scientifiques de niveau recherche, publiés ou non, émanant des établissements d'enseignement et de recherche français ou étrangers, des laboratoires publics ou privés.

\section{다)(1) $(5$}

Distributed under a Creative Commons Attribution - NonCommerciall 4.0 International 


\title{
EFFICIENT ULTRAVIOLET LIGHT FREQUENCY DOWN-SHIFTING BY A THIN FILM OF ZnO NANOPARTICLES
}

\author{
ALEKSANDRA APOSTOLUK*, BRUNO MASENELLI, \\ ELSA TUPIN and BRUNO CANUT \\ Institut des Nanotechnologies de Lyon \\ INL, CNRS-UMR 5270, INSA-Lyon \\ Villeurbanne, F-69621, France \\ *aleksandra.apostoluk@insa-lyon.fr \\ DIMITRI HAPIUK and PATRICE MÉLINON \\ Laboratoire de Physique de la Matière \\ Condensée et Nanostructures, LPMCN, CNR-UMR 5586 \\ Université Claude Bernard Lyon 1 \\ Villeurbanne, F-69622, France \\ JEAN-JACQUES DELAUNAY \\ School of Engineering, The University of Tokyo \\ 7-3-1 Hongo, Bunkyo-ku, Tokyo 113-8656, Japan
}

The maximal efficiency of a single junction solar cell (SC) is defined as the Shockley-Queisser limit, which determines the maximal output power which can be furnished by a $\mathrm{SC}$ as a function of the bandgap of the semiconductor constituting the cell. The short wavelength spectral response of a SC can be improved if a luminescent down-converting layer is added to the SC structure. We propose the use of a layer containing $\mathrm{ZnO}$ nanoparticles (NPs) as a luminescent down-shifter. $\mathrm{ZnO}$ is able to absorb efficiently the ultraviolet light $(\lambda<400 \mathrm{~nm})$, where the SC spectral response is low and to re-emit lower energy photons (longer wavelength photons) for which the SC spectral response is enhanced, thus increasing the total photocurrent. The stoichiometry and crystallinity of ZnO NPs can be controlled and adjusted to obtain the highest visible photoluminescent emission, indicator of an efficient down-shifting. The ratio between the $\mathrm{ZnO}$ UV absorption and visible emission is also estimated and from these results we expect the increase of the SC efficiency using ZnO NPs as a down-shifting layer placed on the front side of the SC.

Keywords: Zinc oxide; nanoparticles; photoluminescence; down-shifting; solar cell. 


\section{Introduction}

Theoretical maximal efficiency of a single junction solar cell (SC) is referred as the Shockley-Queisser limit ${ }^{1}$ and mainly depends on the matching between the solar emission spectrum and the absorption spectrum of the semiconducting material constituting the SC active layer. It places the maximum solar conversion efficiency at around $31 \%$ for a $p-n$ junction made of a material having a bandgap of $1.1-1.3 \mathrm{eV}$ (Si or other widely used semiconductors). In a standard silicon single-junction solar cell only a part of the solar emission spectrum is absorbed: the semiconductor is transparent to the lower energy photons and another fraction of the sun light is lost due to the thermalization phenomenon of highly energetic (short wavelength) photons.

The maximal SC efficiency is limited by its optical absorption, surface reflection, carrier transport and carrier collection. A wide range of approaches was proposed to surpass this efficiency limit: the development of tandem SCs, optical excitation through midgap defect levels, interband transitions, fluorescent down-conversion $(\mathrm{DC})^{2}$ or down-shifting (DS), or thermophotovoltaic DC. ${ }^{3}$

Because of its optical and electrical properties, $\mathrm{ZnO}$ is a very attractive wide bandgap semiconductor and has multiple applications in photoelectrical and optoelectronic devices. Unlike other wide bandgap materials, it is relatively inexpensive, abundant, chemically stable, easy to fabricate, non-toxic and benefits from rather simple crystal growth technology. This results in lower fabrication costs of $\mathrm{ZnO}$-based devices. It has a bandgap of $3.37 \mathrm{eV}(\lambda \approx 367 \mathrm{~nm})$ at room temperature $(\mathrm{RT})$, close to that of GaN (about $3.4 \mathrm{eV}$ at RT). Moreover, $\mathrm{ZnO}$ has a larger exciton binding energy than $\mathrm{GaN}$ (60 meV, 2.4 times larger than $\mathrm{kT}$ at RT), which results in bright UV luminescence emission from free excitons at $\mathrm{RT}$. In the case of the $\mathrm{ZnO}$ nanoparticles (NPs) with perfect crystallinity, only this ultraviolet excitonic luminescence is observed, when excited with a UV laser above the $\mathrm{ZnO}$ bandgap. Our idea is to enhance the green and red luminescence of the $\mathrm{ZnO}$ NPs to the detriment of their UV excitonic emission and apply them as a down-shifting layer placed on the front side of a SC. This green-red PL emission enhancement can be achieved by deliberate introduction of oxygen defects in $\mathrm{ZnO} \mathrm{NP}$ crystal structure, thus making them to be non-stoichiometric.
$\mathrm{ZnO}$ application in SCs is not a new concept: $\mathrm{ZnO}$ : $\mathrm{Al}$ doped (AZO) layers have been used as a transparent electrode in the silicon $\mathrm{SCs},{ }^{4}$ as an antireflective index-matching coating ${ }^{5}$ and $\mathrm{ZnO}$ nanorods and NPs were used an active layer in hybrid SCs. ${ }^{6,7}$

Another material proposed as a down-convertor in SCs is $\mathrm{CdS},{ }^{8}$ but the use of cadmium compounds is still problematic due to their high toxicity.

We propose the application of a film of ZnO NPs as a down-shifting layer to be placed on the front side of a pre-existing commercial SC. This downshifting layer permits to generate one low-energy photon for every incident high-energy photon, thus limiting the front surface recombination of hot photocarriers and thereby enhance the photocurrent generation and the overall conversion efficiency of a SC.

\section{Experimental Details}

\subsection{Fabrication of $\mathrm{ZnO}$ nanoparticles}

$\mathrm{ZnO}$ NPs were fabricated using an original and purely physical method performed in the gas phase: the low energy cluster beam deposition (LECBD). ${ }^{9}$ The nanoparticle's final size (between 6 and $18 \mathrm{~nm}$ ) is influenced by the nozzle shape, chamber volume, and the laser fluence. The NPs' stoichiometry, crystallinity and surface quality can be adjusted via the control of the LECBD synthesis parameters.

A cluster generator based on a combined $\mathrm{Nd}$ : YAG laser vaporization and a rare gas (Ar) condensation source is used to deliver a supersonic jet of NPs with sizes ranging from a few tens to some thousands of atoms (diameters varying from $2 \mathrm{~nm}$ to a few $\mathrm{nm}$ ). The target is a stoichiometric $\mathrm{ZnO}$ powder $(99.99 \%$ pure) which was pressed and heated in a furnace at $1173 \mathrm{~K}$ under oxygen atmosphere for $8 \mathrm{~h}$. The oxygen is injected in the Ar flux present in the nucleation chamber. Different values of the oxygen partial pressure as compared to the Ar pressure were applied in order to obtain the $\mathrm{ZnO}$ NPs with diverse stoichiometry. It should be noted that the deposited $\mathrm{ZnO}$ cluster assembly has the same stoichiometry as the plasma. The nucleation process occurs in a supersonic nozzle, where the atoms are hyper-quenched beyond the thermodynamic equilibrium. The study by transmission electron microscopy (TEM) and X-ray diffraction shows that the NPs are crystallized in the wurtzite structure. Figure 1 presents a high resolution TEM 


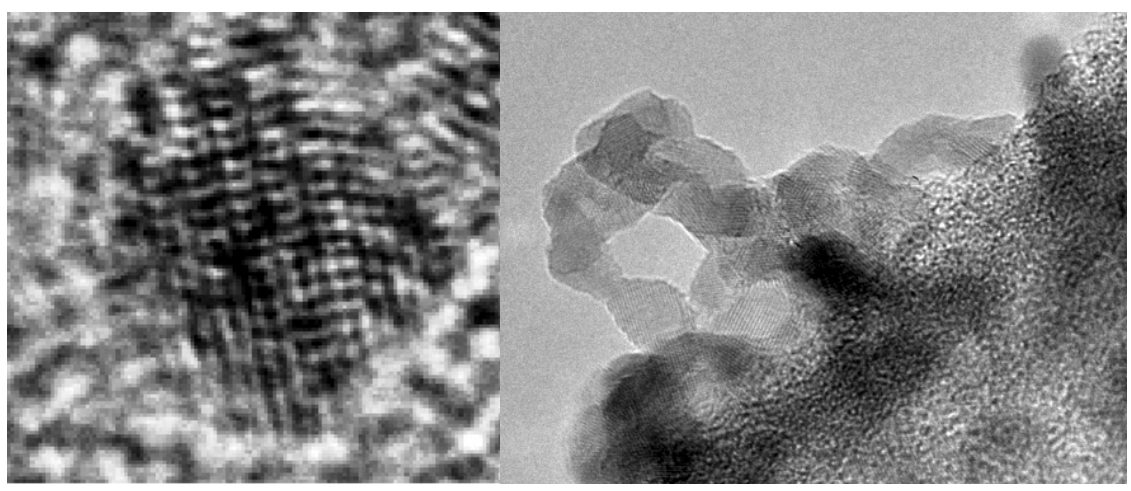

Fig. 1. On the left, a high-resolution TEM image of one $\mathrm{ZnO}$ nanoparticle (the image size is $6.3 \mathrm{~nm} \times 6.3 \mathrm{~nm}$ ), the crystalline structure can be clearly seen; the average size of one NP is $6 \mathrm{~nm}$. On the right, an assembly of several NPs, illustrating the foam-like structure of the deposited $\mathrm{ZnO} \mathrm{NP}$ film.

image of a $\mathrm{ZnO}$ individual NP. The obtained $\mathrm{ZnO}$ NP films are very porous $(\sim 70 \%)$, so we can say that a sort of a foam is fabricated via the LECBD process (cf. Fig. 1 on the right).

\subsection{Absorption and reflectivity measurement}

The absorption and reflectivity of the $\mathrm{ZnO} \mathrm{NP}$ layers were measured using a double beam Perkin Elmer Lambda $900 \mathrm{UV} / \mathrm{VIS} / \mathrm{NIR}$ spectrometer using pre-aligned tungsten-halogen and deuterium lamps as sources.

\subsection{Rutherford backscattering spectrometry study}

The atomic composition and areal mass of the $\mathrm{ZnO}$ NPs films were studied by Rutherford backscattering spectrometry (RBS). The measurements were performed using a beam of ${ }^{4} \mathrm{He}^{+}$ions of $2 \mathrm{MeV}$ energy delivered by the $4 \mathrm{MV}$ Van de Graaff accelerator of the Nuclear Physics Institute of Lyon (IPNL). The backscattered particles were detected with a $13 \mathrm{keV}$-resolution implanted Si junction, set at an angle of $172^{\circ}$ with respect to the incident ion beam axis.

\subsection{Photoluminescence study}

The RT photoluminescence (PL) experiments were performed with a frequency doubled argon laser operating at $244 \mathrm{~nm}$ (Lexel $95 \mathrm{SHG}$ ). The PL signal of $\mathrm{ZnO}$ NPs was dispersed using a Jobin-Yvon HR 640 monochromator with a 600 lines/mm grating blazed at $400 \mathrm{~nm}$ and then detected with a GaAs
(Hamamatsu H5701-50) photomultiplier. In all cases the spectra are corrected from the spectral response of the system and normalized to their maximum.

\section{Experimental Results}

It has been already demonstrated that depending on the method of the incorporation of oxygen into the NPs during the LECBD process, clusters with identical stoichiometry exhibit very different PL properties. ${ }^{9}$ The post-deposition exposition to oxygen does not improve in a significant manner the stoichiometry of the $\mathrm{ZnO} \mathrm{NPs}^{10}$ Thus, for the fabrication of non-stoichiometric ZnO NPs having efficient green and red luminescence (necessary for $\mathrm{DC}$ ), we need to vary the oxygen pressure in the plasma during the LECBD process.

We observed that the ratio between the excitonic and the green-red PL emission band can be adjusted via the variation of the value of the partial oxygen pressure in the plasma applied during the LECBD of the $\mathrm{ZnO}$ NPs. ${ }^{11} \mathrm{ZnO}$ NPs deposited as thin porous layers (several tenths of nm thick) under various oxygen partial pressures were studied: $25 \%$ of the oxygen in the buffer gas (resulting in stoichiometric $\mathrm{ZnO}_{x} \mathrm{NPs}, x=1$ ), then $12.5 \%$ and $7 \%$ of the oxygen in the buffer gas (these last two values resulted in nonstoichiometric $\mathrm{ZnO}_{x}$, with theoretical values of $x=0.5$ and 0.28 , respectively, as deduced from the calibration based on the X-ray photoelectron spectroscopy (XPS) measurements ${ }^{10}$ ).

The stoichiometry and areal mass of the fabricated NPs were measured by RBS. It showed that in the case of all studied samples nanoparticles are stoichiometric $(x=1)$, though the LECBD 


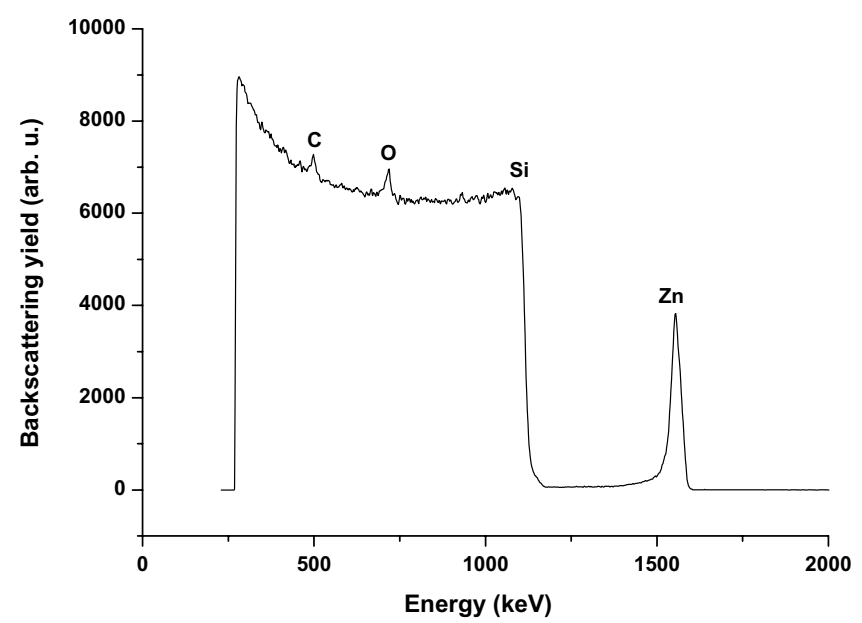

Fig. 2. RBS spectrum recorded on $\mathrm{ZnO}_{x}$ NPs with a theoretical value of $x=0.28$. The RBS measurements indicate that within the experimental uncertainties, the deposited NPs are stoichiometric (measured value: $x=1$ ) and their areal mass is $7.8 \mu \mathrm{g} \cdot \mathrm{cm}^{-2}$. Analysis conditions: ${ }^{4} \mathrm{He}^{+}$ions of $2 \mathrm{MeV}$ energy; detection angle of $172^{\circ}$.

parameters used during the fabrication of the two of them (these deposited with $12.5 \%$ and $7 \%$ of the oxygen in the buffer gas) should permit to fabricate the $\mathrm{ZnO}$ NPs with oxygen vacancies (thus nonstoichiometric $\mathrm{ZnO}_{x}$ ). In the RBS spectrum shown in Fig. 2, the expected oxygen content was $x=0.28$. The only "unusual" peak observed in this spectrum is the carbon signal. It indicates that there was some residual pollution present on the studied sample. The LECBD plasma parameters (oxygen and argon partial pressures), the theoretical oxygen content and oxygen content measured by RBS for all studied samples are summarized in Table 1.

All ZnO NPs films were exposed to the ambient air after deposition and as they are very porous, we concluded that the oxygen adsorption at the NPs surface occurred. This adsorbed oxygen filled the oxygen vacancies at the NPs surface. High roughness and porosity of the ZnO NPs films (which facilitates oxygen adsorption) are evidenced in the low energy tail of the Zn peak observed in the RBS spectrum presented in Fig. 2. It should be also noted that the intensity of the defect-related emission of the PL spectrum (between $\sim 1.7 \mathrm{eV}$ and $\sim 3.1 \mathrm{eV}$ ) of the ZnO NPs was increased after the exposition of the NPs to the ambient air. ${ }^{11}$

The influence of the oxygen partial pressure applied during the LECBD on the enhancement of the green and red luminescence emitted by $\mathrm{ZnO}$ NPs was studied by the UV-excited PL at RT. The
Table 1. Parameters of the plasma used during the ZnO NPs deposition by the LECBD technique, resulting theoretical $\mathrm{ZnO}_{x}$ stoichiometries (as deduced from the calibration based on the XPS measurements ${ }^{10}$ ) and the content of each element ( $\mathrm{Zn}$ and $\mathrm{O}$ ) detected by RBS (the RBS measurement error is $\pm 2 \%$ ).

\begin{tabular}{lccc}
\hline $\begin{array}{c}\text { Oxygen partial pressure } \\
\text { in the LECBD plasma }\end{array}$ & 1.4 mbar & 2.5 mbar & 5 mbar \\
$\begin{array}{c}\text { Argon partial pressure in } \\
\text { the LECBD plasma }\end{array}$ & 18.6 mbar & 17.5 mbar & 15 mbar \\
$\begin{array}{c}\text { Theoretical oxygen } \\
\text { content } x \text { in ZnO }\end{array}$ & $x=0.28$ & $x=0.5$ & $x=1$ \\
$\begin{array}{c}\text { ZnO nanoparticles } \\
\text { theoretically } \\
\text { stoichiometric? }\end{array}$ & No & No & Yes \\
$\begin{array}{c}\text { Oxygen content }(x) \\
\text { measured by RBS }\end{array}$ & 1.04 & 1 & 1.02 \\
\hline
\end{tabular}

absorption and reflectance of the $\mathrm{ZnO} \mathrm{NP}$ layers were also measured in order to determine the ability of $\mathrm{ZnO}$ NPs of the efficient light harvesting and down-shifting. The $\mathrm{ZnO}$ NP film absorption is presented in Fig. 3, together with the UV-visible conversion quantum yield.

In order to estimate the conversion quantum yield of the $\mathrm{ZnO} \mathrm{NPs}$, at first we studied the PL excited with a UV laser at $244 \mathrm{~nm}$ in function of the LECBD parameters. Two PL peaks were observed for all samples - the excitonic emission in the UV (at $378 \mathrm{~nm}$ ) and the defect-related green-red lumi-

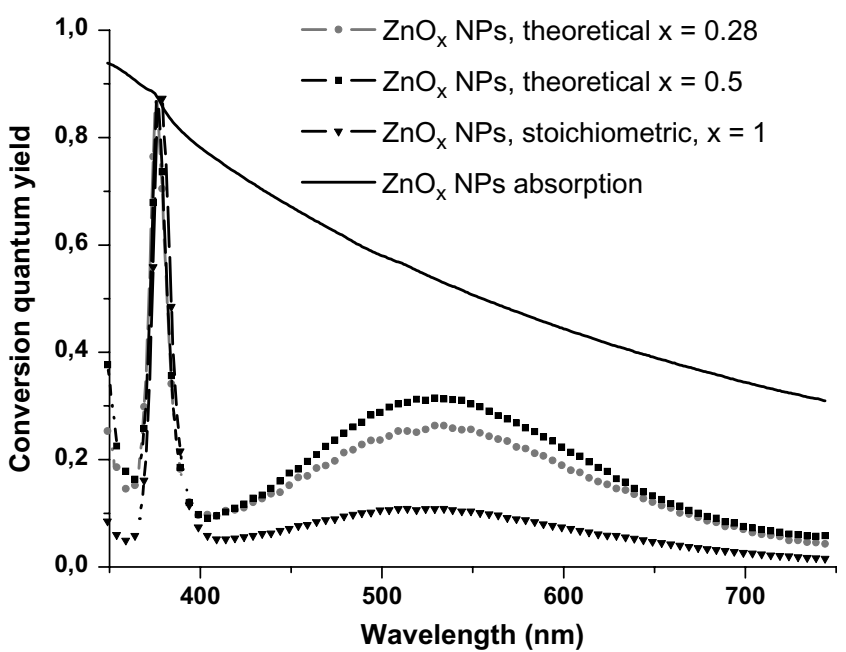

Fig. 3. The conversion quantum yield of the $\mathrm{ZnO}_{x} \mathrm{NPs}_{\mathrm{s}}$ as a function of their theoretical stoichiometry (calculated from the LECBD plasma composition and using the calibration based on the XPS measurement ${ }^{10}$ ). It can be clearly noticed that the maximum UV-visible conversion efficiency is observed for the sample with a theoretical stoichiometry of $x=0.5$. The absorption spectrum of the $\mathrm{ZnO} \mathrm{NP}$ layer is also shown. 
nescence. ${ }^{11}$ This visible PL is due to the oxygen vacancies in the $\mathrm{ZnO}$ crystal lattice. We clearly observed the enhancement of the green and red emission in non-stoichiometric $\mathrm{ZnO} \mathrm{NPs}$, when compared to the PL signal from the stoichiometric ones. ${ }^{11}$ The excitonic contribution to the PL signal, located at $378 \mathrm{~nm}(\sim 3.28 \mathrm{eV})$ was already observed for other $\mathrm{ZnO}$ nanostructures. The defect-related green luminescence band is generally observed around $530 \mathrm{~nm}$. It should also be noted that the ratio between the excitonic and the defect related emission is often used as an indirect probe of the $\mathrm{ZnO}$ film crystalline quality.

The stronger green-red emission, the better will be down-shifting in $\mathrm{ZnO}$, as it is a proof that it absorbs the UV light and emits the green-red light efficiently. The highest green-red PL intensity was observed in the case of the $\mathrm{ZnO}_{x} \mathrm{NP}$ film for which the theoretical value of $x=0.5$ (which corresponds to $12.5 \%$ oxygen in the plasma in the $\mathrm{LECBD}^{11}$ ). Thus we concluded that there exists an optimal partial oxygen pressure in the buffer gas (plasma) injected during the LECBD, which permits to obtain the $\mathrm{ZnO}$ NPs of poor crystalline quality, with many oxygen vacancies present in the crystal structure.

We quantified the UV-visible conversion quantum yield in the $\mathrm{ZnO} \mathrm{NP}$ film (shown in Fig. 3 together with the $\mathrm{ZnO} \mathrm{NP}$ film absorption) assuming that all absorbed UV photons are re-emitted in a radiative manner (i.e. there is not any nonradiative recombination), which is of course an ideal situation. Obtained results suggests that for some reason the $\mathrm{ZnO}_{x}$ with the theoretical value of $x=$ 0.5 (as deduced from the calibration based on the $\mathrm{XPS}^{10}$ ) is better for the $\mathrm{DC}$ than the $\mathrm{ZnO}_{x}$ with $x=0.28$. As can be noticed in Fig. 3, the maximal value of the UV-visible conversion efficiency in the ideal case, where the radiative recombination is the only possible way of disexcitation, is estimated at about $30 \%$, though this value should be confirmed by the measurements of the efficiencies of the final photovoltaic devices.

\section{Conclusions and Perspectives}

In this paper, $\mathrm{ZnO}$ NPs deposited by a purely physical method - the LECBD - were studied. The crystalline quality of the fabricated NPs was proven by the HRTEM analysis. The NP size is of about $6 \mathrm{~nm}$. Two contributions to the PL emission spectrum of $\mathrm{ZnO}$ NPs were observed - the excitonic one at around $378 \mathrm{~nm}$ and the defect-related one in the $400-700 \mathrm{~nm}$ spectral range. We quantified the $\mathrm{ZnO} \mathrm{NP}$ film conversion quantum yield and it turned out to be of about $30 \%$ in the UV-visible region. Further work will concern the application of these ZnO NPs as a down-shifting layer placed on the front side of a commercially available silicon solar cell, and we expect the increase of the efficiency of such a device.

\section{Acknowledgments}

The $\mathrm{ZnO}$ nanoparticles we studied were fabricated using the research facilities of the PLYRA (Plateforme LYonnaise de Recherche sur les Agrégats) platform at the Lyon 1 university. The authors acknowledge Olivier Boisron for his kind assistance during the $\mathrm{ZnO}$ nanoparticle layer deposition.

\section{References}

1. W. Shockley and H. J. Queisser, J. Appl. Phys. 32, 510 (1961).

2. A. S. Brown and M. A. Green, J. Appl. Phys. 92, 1329 (2002).

3. B. Jalali, S. Fathpour and K. Tsia, Opt. Photonics News 20, 18 (2009).

4. Z. C. Zin, I. Hamberg and C. G. Granqvist, J. Appl. Phys. 64, 5117 (1988).

5. Y.-J. Lee, D. S. Ruby, D. W. Peters, B. B. McKenzie and J. W. P. Hsu, Nano Lett. 8, 1501 (2008).

6. W. J. E. Beek, M. M. Wienk and R. A. J. Janssen, Adv. Mater. 16, 1009 (2004).

7. W. J. E. Beek, M. M. Wienk, M. Kemerink, X. Yang and R. A. J. Janssen. J. Phys. Chem. B 109, 9505 (2005).

8. M. S. Saidov, Appl. Sol. Energy 43, 161 (2007).

9. A. Perez, P. Mélinon, V. Dupuis, P. Jensen, B. Prevel, J. Tuaillon, L. Bardotti, C. Martet, M. Treilleux, M. Broyer, M. Pellarin, J. L. Vaille, B. Palpant and J. Lerme, J. Phys. D: Appl. Phys. 30, 709 (1997).

10. D. Tainoff, B. Masenelli, O. Boisron, G. Guiraud and P. Mélinon, J. Phys. Chem. C 112, 12623 (2008).

11. A. Apostoluk, B. Masenelli, Y. Zhu, B. Canut, D. Hapiuk and J. J. Delaunay, paper in preparation. 